\title{
Disinhibition Opens the Gate to Pathological Pain Signaling in Superficial Neurokinin 1 Receptor-Expressing Neurons in Rat Spinal Cord
}

\author{
Carole Torsney ${ }^{1}$ and Amy B. MacDermott ${ }^{1,2}$ \\ ${ }^{1}$ Department of Physiology and Cellular Biophysics and ${ }^{2}$ Center for Neurobiology and Behavior, Columbia University, New York, New York 10032
}

\begin{abstract}
Blockade of local spinal cord inhibition mimics the behavioral hypersensitivity that manifests in chronic pain states. This suggests that there is a pathway capable of mediating allodynia/hyperalgesia that exists but is normally under strong inhibitory control. Lamina I and III neurokinin 1 (NK1) receptor expressing (NK1R + ) dorsal horn neurons, many of which are projection neurons, are required for the development of this hypersensitivity and are therefore likely to be a component of this proposed pathway. To investigate, whole-cell patch-clamp recordings were made from lamina I and III NK1R + neurons in the spinal cord slice preparation with attached dorsal root. Excitatory postsynaptic currents were recorded in response to electrical stimulation of the dorsal root. Lamina I NK1R + neurons were shown to receive high-threshold (A $\delta / C$ fiber) monosynaptic input, whereas lamina III NK1R + neurons received low-threshold (A $\beta$ fiber) monosynaptic input. In contrast, lamina I neurons lacking NK1 receptor $(\mathrm{NK1R}-)$ received polysynaptic A fiber input. Blockade of local GABAergic and glycinergic inhibition with bicuculline $(10 \mu \mathrm{M})$ and strychnine $(300 \mathrm{nM})$, respectively, revealed significant A fiber input to lamina I NK1R + neurons that was predominantly $\mathrm{A} \beta$ fiber mediated. This novel A fiber input was polysynaptic in nature and required NMDA receptor activity to be functional. In lamina I NK1R - and lamina III NK1R + neurons, disinhibition enhanced control-evoked responses, and this was also NMDA receptor dependent. These disinhibition-induced changes, in particular the novel polysynaptic low-threshold input onto lamina I NK1R + neurons, may be an underlying component of the hypersensitivity present in chronic pain states.
\end{abstract}

Key words: nociceptors; dorsal horn; low threshold; primary afferent; NMDA receptor; inhibition

\section{Introduction}

Chronic pain states result in behavioral hypersensitivity, consisting of increased pain responses to noxious stimulation (hyperalgesia) and pain responses to normally innocuous stimuli (allodynia). The behavioral phenomenon of allodynia can be induced by intrathecal administration of the $\mathrm{GABA}_{\mathrm{A}}$ antagonist, bicuculline, or the glycine receptor antagonist strychnine (Yaksh, 1989). Similarly, the nociceptive flexion withdrawal reflex shows increased responses to noxious stimuli (strychnine) and novel responses to low-threshold input (strychnine/bicuculline) after intrathecal administration of the antagonists (Sivilotti and Woolf, 1994). Removal of GABAergic inhibition has also been shown to facilitate low-threshold input to the superficial dorsal horn (Baba et al., 2003). Importantly, disruption of inhibitory mechanisms is a common feature of a variety of chronic pain states, including those resulting from inflammation (Harvey et al., 2004), nerve injury (Moore et al., 2002; Coull et al., 2003; Scholz et al. 2005), and spinal cord injury (Drew et al., 2004).

\footnotetext{
Received May 31, 2005; revised Dec. 18, 2005; accepted Dec. 19, 2005.

This work was supported by National Institutes of Health Grant NS029797 and by New York State Department of Health Spinal Cord Injury Research Program Grant C018608.

Correspondence should be addressed to Dr. Carole Torsney, Department of Physiology, Columbia University, 630 West 168th Street, New York, NY 10032. E-mail: ct2035@columbia.edu.

D0I:10.1523/JNEUROSCI.4584-05.2006

Copyright $\odot 2006$ Society for Neuroscience $\quad$ 0270-6474/06/261833-11\$15.00/0
}

Neurons in lamina I and III of the dorsal horn that express neurokinin 1 receptor $(\mathrm{NK} 1 \mathrm{R}+)$ are critical for the development of injury-induced hypersensitivity. Selective ablation of these $\mathrm{NK} 1 \mathrm{R}+$ neurons with a substance $\mathrm{P}$ and saporin conjugate (SPSAP) attenuates allodynia/hyperalgesia in a variety of chronic pain models (Mantyh et al., 1997; Nichols et al., 1999). In vivo extracellular recordings from dorsal horn neurons in animals lacking these neurons (SP-SAP treated) reveal that lamina I and III NK1R + neurons are required for the development of central sensitization (Khasabov et al., 2002), which involves a supraspinal loop (Suzuki et al., 2002; Khasabov et al., 2005). However, the interplay between local spinal circuits and NK1R + lamina I and III neurons has not been directly assessed.

Importantly, a significant proportion of lamina I and III NK1R+ neurons project to higher brain centers (Marshall et al., 1996; Todd et al., 2000; Spike et al., 2003). They receive noxious input as evidenced by NK1 receptor internalization (Mantyh et al., 1995) and c-Fos expression (Doyle and Hunt, 1999). Furthermore, capsaicin increases the frequency of miniature EPSCs in these neurons, indicating that they receive direct input from capsaicin and heat-sensitive nociceptors (Labrakakis and MacDermott, 2003).

Given that spinal disinhibition mimics chronic pain hypersensitivity, we propose that there is a dorsal horn pathway capable of mediating allodynia/hyperalgesia that exists but is under 
strong inhibitory control. Notably, inhibitory interneurons are present throughout this region; $30-40 \%$ of neurons in lamina I-III are immunoreactive for GABA, and glycine coexists in a subpopulation of these neurons (Todd and Sullivan, 1990). As many lamina I and III NK1R+ neurons are projection neurons and are required for the development of allodynia/hyperalgesia, these neurons are likely to be a component of the proposed pathway. To test this hypothesis, we characterized primary afferent synaptic input to lamina I and III NK1R + neurons under control conditions and then in the presence of the local inhibitory blockers bicuculline $(10 \mu \mathrm{M})$ and strychnine $(300 \mathrm{~nm})$. For comparison, recordings were also made from lamina I neurons lacking the NK1R (NK1R-).

\section{Materials and Methods}

Spinal cord slice preparation. Postnatal rats [postnatal day 17 ((P17) to P22] were anesthetized with isoflurane and decapitated, and the lumbar (L4/L5) region of the spinal cords was removed in a manner approved by the Columbia University Institutional Animal Care and Use Committee. The spinal cords were initially placed in ice-cold dissection solution then embedded in an agarose block and cut into transverse slices $(350 \mu \mathrm{m})$ with attached dorsal roots. Slices were incubated in oxygenated recovery solution at $35^{\circ} \mathrm{C}$ for $1 \mathrm{~h}$ and then incubated with $20 \mathrm{~nm}$ tetramethylrhodamine-conjugated substance P (TMR-SP) for 20 min at room temperature (Labrakakis and MacDermott, 2003) and allowed to recover for $1 \mathrm{~h}$ before recording. Slices were transferred to an upright microscope equipped with fluorescence for identification of positive neurons and IR-DIC for electrophysiological recordings. Slices were continuously perfused with oxygenated Krebs at a flow rate of $2 \mathrm{ml} / \mathrm{min}$. Recordings were made at room temperature. $95 \% \mathrm{O}_{2} / 5 \% \mathrm{CO}_{2}$ saturated Krebs solution had the following composition (in mM): $125 \mathrm{NaCl}, 2.5$ $\mathrm{KCl}, 1.25 \mathrm{NaH}_{2} \mathrm{PO}_{4}, 26 \mathrm{NaHCO}_{3}, 25$ glucose, $1 \mathrm{MgCl}_{2}, 2 \mathrm{CaCl}_{2}, \mathrm{pH}$ 7.4. Recovery solution was the same as Krebs but with $1.5 \mathrm{CaCl}_{2}$ plus $6 \mathrm{MgCl}_{2}$. Dissection solution was the same as recovery solution but with $1 \mathrm{~mm}$ kynurenic acid.

This postnatal age $(\sim \mathrm{P} 21)$ was chosen because the postnatal development of dorsal horn sensory processing is mostly complete (Fitzgerald, 2005), although afferent synaptic input is further refined into adulthood (Park et al., 1999; Nakatsuka et al., 2000). Furthermore, it is possible to record from "identified" spinal cord neurons, which becomes increasingly difficult with heavier laminar myelination at older postnatal ages.

Patch-clamp recording. Whole-cell patch configuration was used to record EPSCs from identified neurons while the dorsal root was stimulated with a suction electrode. Intracellular solution had the following composition (in mM): 120 Cs-Methylsulfonate, $10 \mathrm{Na}$-Methylsulfonate, 10 EGTA, $1 \mathrm{CaCl}_{2}, 10$ HEPES, 5 lidocaine $N$-ethyl bromide quaternary salt $\mathrm{Cl}, 2 \mathrm{Mg}^{2+}$-ATP, $\mathrm{pH}$ adjusted to 7.2 with $\mathrm{CsOH}$, osmolarity 280. In some cases, $1 \mu \mathrm{M}$ Alexa Fluor 488 hydrazide was included in the recording pipette. Junction potential was corrected before recording. Data were recorded and acquired using an Axopatch 200 amplifier and pClamp 9 software (Molecular Devices, Union City, CA). Data were filtered at 5 $\mathrm{kHz}$ and digitized at $50 \mathrm{kHz}$.

Dorsal root stimulation. To assess primary afferent input, the synaptic response-stimulus intensity profile for each neuron was determined by systematically increasing the stimulation intensity from 0 to $500 \mu \mathrm{A}$ (ISO-Flex Stimulus Isolator; A.M.P.I., Jerusalem, Israel) using a lowstimulation frequency of $0.05 \mathrm{~Hz}$ (duration, $0.1 \mathrm{~ms}$ ). Stimulus threshold ranges and averages for each primary afferent fiber type at this postnatal rat age (P21) have been reported: $\mathrm{A} \beta$ fibers $8-26,25 \pm 2.5 \mu \mathrm{A}$ (range, mean $\pm \mathrm{SE}$ ); A $\delta$ fibers $25-82,67 \pm 37.9 \mu \mathrm{A}$; and $\mathrm{C}$ fibers $180-420$, $319 \pm 46 \mu \mathrm{A}$ (Nakatsuka et al., 2000). Therefore, the stimulus intensities used in our experiments were $4,8,12$, and $25 \mu \mathrm{A}$ for $\mathrm{A} \beta, 50$ and $100 \mu \mathrm{A}$ for $\mathrm{A} \delta$, and $500 \mu \mathrm{A}$ for $\mathrm{C}$ fiber input. Stimulus intensity was increased every minute, allowing recording of three EPSCs at each intensity tested, ensuring systematic activation of first A then C fibers in the root. Response stability was used to discriminate between EPSCs that were "evoked" and therefore time-locked with the stimulus and responses that were spontaneous and therefore unconnected with the stimulus. At this low frequency of stimulation, both monosynaptic and polysynaptic responses could be seen as stable responses.

Stable, afferent input was then dissected into mono and polysynaptic components, in the same manner as that in the study by Nakatsuka et al. (2000). They showed that action potential firing in $C$ fibers begins to fail at stimulation frequencies $>1 \mathrm{~Hz}$, in $\mathrm{A} \delta>2 \mathrm{~Hz}$, but in $\mathrm{A} \beta$ fibers did not fail even at $20 \mathrm{~Hz}$. Therefore, the dorsal root was stimulated $(20 \times)$ at these frequencies and intensities $(25 \mu \mathrm{A}, 20 \mathrm{~Hz} ; 100 \mu \mathrm{A}, 2 \mathrm{~Hz}$, and sometimes $10 \mathrm{~Hz} ; 500 \mu \mathrm{A}, 1 \mathrm{~Hz}$ ) to assess the monosynaptic/polysynaptic nature of the $\mathrm{A} \beta, \mathrm{A} \delta$, and $\mathrm{C}$ fiber inputs, respectively. If we stimulated at frequencies higher than those stated, we would not be able to distinguish a failure of primary afferent fibers to fire action potentials from that of a synaptic failure. For A fiber-evoked EPSCs, an absence of synaptic failures and a stable latency $(<2 \mathrm{~ms})$ was considered monosynaptic, whereas synaptic failures and/or latency variability $(>2 \mathrm{~ms})$ was considered polysynaptic. In most neurons, the dorsal root was stimulated at a frequency of $10 \mathrm{~Hz}$ in addition to $2 \mathrm{~Hz}$ at the $100 \mu \mathrm{A}$ stimulation intensity, as many $\mathrm{A} \delta$ fibers can still fire action potentials at this rate. Testing at this frequency allows more rigorous testing of the monosynaptic/polysynaptic nature of the response. Interestingly, in most neurons tested, dorsal root stimulation at $10 \mathrm{~Hz}$ did not discount responses identified as monosynaptic at the $2 \mathrm{~Hz}$ stimulation rate, suggesting that most of the recorded $\mathrm{A} \delta$ fiber inputs can repetitively fire action potentials at $10 \mathrm{~Hz}$. For C-fiber EPSCs evoked at $1 \mathrm{~Hz}$, a lack of synaptic failures was considered evidence of monosynaptic input, even if there was a prolongation of latency (Nakatsuka et al., 2000), whereas a response showing synaptic failures was considered polysynaptic. Although a $1 \mathrm{~Hz}$ stimulation rate is a less rigorous test of monosynaptic versus polysynaptic, it was used to classify $\mathrm{C}$ fiber inputs, because higher frequencies would lead to the misidentification of monosynaptic $\mathrm{C}$ fiber inputs as polysynaptic.

Analysis. To generate a synaptic response-stimulus intensity profile, synaptic activity was analyzed by measuring the area under the curve from the stimulus artifact to the end of the trace $(900 \mathrm{~ms})$ for each of the three EPSCs at each intensity tested $(4,8,12,25,50,100$, and $500 \mu \mathrm{A})$ using Clampfit 9 Software (Molecular Devices). For each cell, repeatedmeasures ANOVA followed by Newman-Keuls posttests were used to compare the average EPSC area, between conditions, at each stimulation intensity independently. All averaged data are represented as mean $\pm \mathrm{SE}$. Asterisks indicate that bicuculline plus strychnine is significantly different from all other conditions $\left({ }^{*} p<0.05,{ }^{* *} p<0.01,{ }^{* * *} p<0.001\right)$.

Materials. TMR-SP and Alexa Fluor 488 were purchased from Invitrogen (Eugene, OR). Bicuculline, D-APV, and 2,3-dihydroxy-6-nitro-7sulfonyl-benzo[f] quinoxaline-7-sulfonamide (NBQX) were purchased from Tocris Cookson (Ellisville, MO). Strychnine was obtained from Sigma (St. Louis, MO).

\section{Results}

\section{Differential primary afferent synaptic input to lamina I and III NK1R+ and lamina I NK1R - neurons}

Whole-cell patch configuration was used to record EPSCs from lamina I and III NK1R + neurons and also lamina I NK1Rneurons (holding potential, $-70 \mathrm{mV}$ ). The dorsal root was stimulated over a range of intensities and frequencies to characterize the primary afferent input and its monosynaptic/polysynaptic nature. Figure $1 A$ shows an example of a lamina I NK1R+ neuron identified after incubation with $20 \mathrm{nM}$ TMR-SP. The recording pipette often contained $1 \mu \mathrm{M}$ Alexa Fluor 488 hydrazide to confirm that the neuron labeled with TMR-SP was that recorded from under IR-DIC (Fig. 1Aiii).

In our preparation, TMR-SP labels a small proportion of lamina I neurons (on average, 5-10 neurons per slice), clearly less than the $45 \%$ of lamina I neurons reported to express NK1 receptor (Todd et al., 1998). Given that most lamina I projection neurons ( $5 \%$ of all lamina I neurons) that express NK1 receptor do so at moderate to strong levels (Spike et al., 2003) we are more apt to be targeting this projection neuron population rather than the 

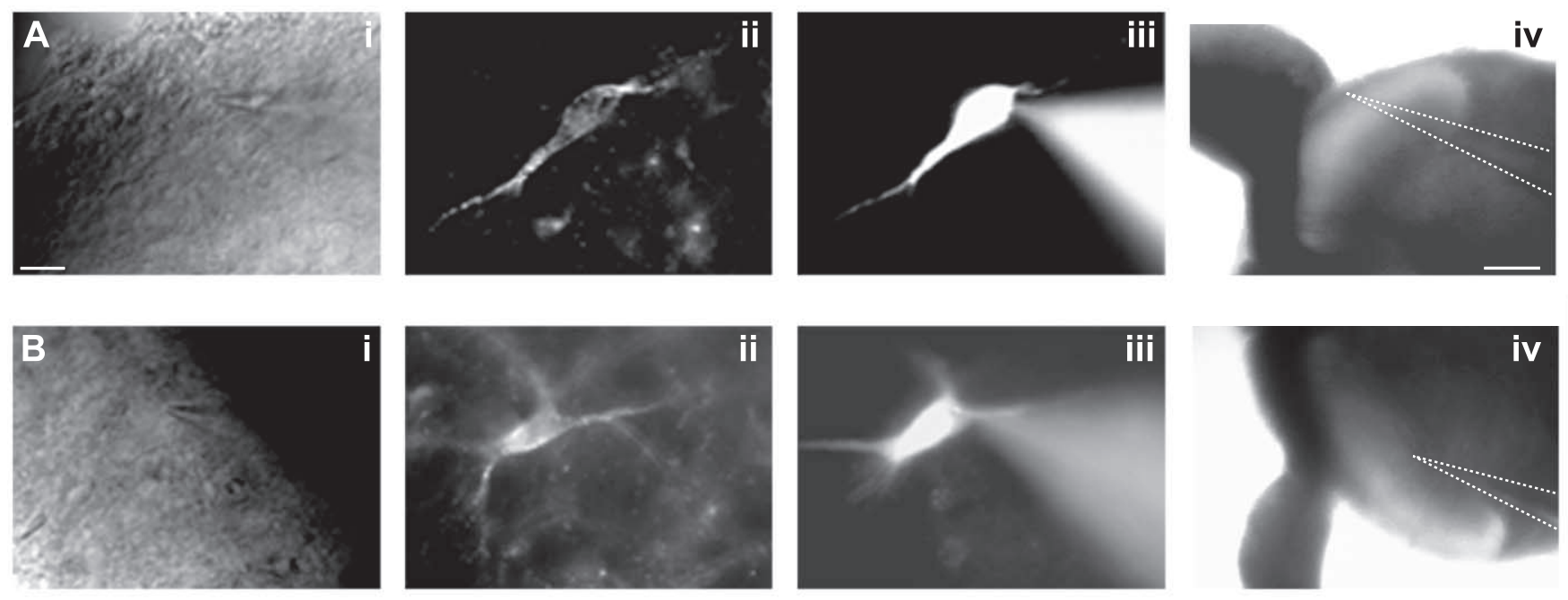

Figure 1. TMR-SP labeling of a lamina I neuron $(\boldsymbol{A})$ and a lamina III neuron $(\boldsymbol{B})$. $\boldsymbol{i}$-iii, IR-DIC image of a neuron (i) visualized with TMR-SP fluorescence (ii) and filled with Alexa Fluor 488 hydrazide (iii). A recording pipette can be seen in $\boldsymbol{i}$ and iii. iv, The location of the recording pipette is shown at low magnification and is outlined for clarity. In $A$, the tip of the recording pipette is located in lamina I and is clearly dorsal to the relatively translucent band corresponding to the substantia gelatinosa. In $\boldsymbol{B}$, the tip of the recording pipette is located just ventral to the substantia gelatinosa in lamina III. Scale bar: i-iii, $20 \mu \mathrm{m} ; \boldsymbol{i v}, 200 \mu \mathrm{m}$.

population of weakly NK1 receptor immunoreactive neurons (Cheunsuang and Morris, 2000) that are likely to be interneurons (Todd et al., 2005).

Lamina I NK1R + neurons could easily be distinguished from lamina III NK1R + neurons because of the paucity of NK1R+ neurons in lamina II (Bleazard et al., 1994; Brown et al., 1995). When targeting lamina III NK1R+ neurons, effort was made to record from labeled neurons just ventral to the unlabeled area corresponding to lamina II, but we cannot exclude the possibility that some of these neurons were within lamina IV. Figure $1 B$ shows an example of an NKIR + neuron identified in lamina III. Lamina I NK1R - neurons were targeted in slices similarly incubated with TMR-SP to ensure lack of NK1R expression in the recorded neuron. Recordings were made from unlabeled neurons in proximity to and the same depth as lamina I NK1R+ neurons to rule out false negatives because of decreasing penetration of TMR-SP as slice depth increased. Laminar location of the recording pipette was always confirmed at the end of the experiment using low magnification $(4 \times)$ allowing us to observe that recordings were either dorsal (lamina I) or ventral (lamina III) to the relatively translucent lamina II (Fig. 1 Aiv,Biv).

Our technique for preidentifying NK1R + neurons is expected to have little impact on the synaptic activity we are studying. TMR-SP is one of the least biologically active of fluorescenceconjugated substance $\mathrm{P}$ analogs and does not inhibit neuronal M-type $\mathrm{K}^{+}$current at the nanomolar concentration used in our study, although it does elevate calcium in Chinese hamster ovary cells expressing NK1 receptor (Bennett and Simmons, 2001). Moreover, previous data from our laboratory has shown that TMR-SP does not appear to alter dorsal root evoked synaptic activity in NK1R+ neurons identified in this manner (C. K. Tong, unpublished observation).

Dorsal root stimulation at different intensities and frequencies was used to establish the nature of the primary afferent input to lamina I NK1R+ neurons. Figure $2 \mathrm{~A}$ shows an example of EPSCs recorded from a lamina I NK1R + neuron that received monosynaptic $C$ fiber input. Low-frequency dorsal root stimulation $(0.1 \mathrm{~ms}, 0.05 \mathrm{~Hz} ; 3 \times)$ at $\mathrm{A} \beta(25 \mu \mathrm{A})$ and $\mathrm{A} \delta$ fiber $(100 \mu \mathrm{A})$ intensities evoked negligible and small EPSCs, respectively, whereas stimulation at $\mathrm{C}$ fiber intensity $(500 \mu \mathrm{A})$ clearly evoked a response (Fig. 2Ai). High-frequency stimulation revealed that the small $\mathrm{A} \delta$ fiber evoked response was polysynaptic, because the response sometimes failed. The $\mathrm{C}$ fiber evoked response was shown to be monosynaptic in nature as high-frequency stimulation reliably evoked EPSCs (Fig. 2Aii).

Figure $2 B$ shows an example of EPSCs recorded from a lamina $\mathrm{I} \mathrm{NK} 1 \mathrm{R}+$ neuron that received monosynaptic $\mathrm{A} \delta$ fiber input. Dorsal root stimulation did not evoke EPSCs until the stimulation intensity was sufficient to activate $\mathrm{A} \delta$ fibers $(100 \mu \mathrm{A})$ (Fig. $2 \mathrm{Bi}$ ). The response was reliably evoked after high-frequency $(2$ $\mathrm{Hz}$ ) stimulation with little variability in latency $(<2 \mathrm{~ms})$ (Fig. $2 \mathrm{Bii}$ ). This monosynaptic response profile was also generated by stimulating the dorsal root at the higher frequency of $10 \mathrm{~Hz}$ (data not shown). Stimulation at $\mathrm{C}$ fiber intensity revealed additional components, which were also monosynaptic in nature, because there is a second longer latency component that does not fail during high-frequency stimulation (Fig. 2 Bii).

Lamina I NK1R + neurons $(n=21)$ were generally found to receive high-threshold monosynaptic input, either $C$ fiber (11 of 21 ) and/or A $\delta$ fiber ( 6 of 21) monosynaptic input. Other NK1R+ neurons received $\mathrm{C}$ fiber and/or A $\delta$ fiber input (6 of 21) that was polysynaptic in nature. Only four lamina I NK1R+ neurons showed any evidence of polysynaptic $\mathrm{A} \beta$ fiber input. The primary afferent input to lamina I NK1R + neurons is summarized in Table 1, and the predominant input is illustrated in Figure $2 C$.

Lamina I NK1R - neurons $(n=6)$ received polysynaptic $\mathrm{A} \beta$ ( 3 of 6 ) and/or polysynaptic $\mathrm{A} \delta$ (5 of 6 ) fiber input. Figure $2 D$ shows EPSCs recorded from a lamina I NK1R - neuron with polysynaptic $\mathrm{A} \beta$ and polysynaptic $\mathrm{A} \delta$ fiber input. Dorsal root stimulation clearly evokes a response at $25 \mu \mathrm{A}, \mathrm{A} \beta$ fiber intensity (Fig. $2 \mathrm{Di}$ ). This response fails when stimulated at high frequency $(20 \mathrm{~Hz})$, indicating that it is polysynaptic in nature (Fig. 2 Dii). Stimulation at $\mathrm{A} \delta$ fiber intensities further increases response magnitude, and high-frequency stimulation produces a variable latency response $(>2 \mathrm{~ms})$ demonstrating that the additional $\mathrm{A} \delta$ fiber input is also polysynaptic. The predominance of polysynaptic A fiber input to lamina I NK1R - neurons clearly differs from the strong high-threshold monosynaptic input to lamina I 


\section{Lamina I NK1R+}

A

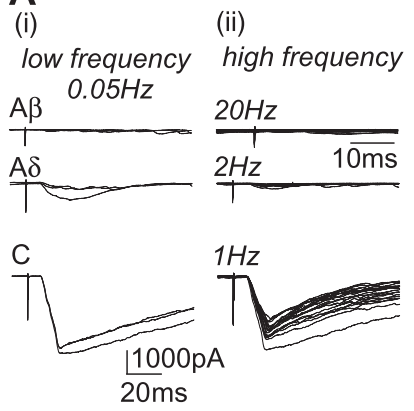

polysynaptic $A \delta+$ monosynaptic $\mathrm{C}$
B

(i)

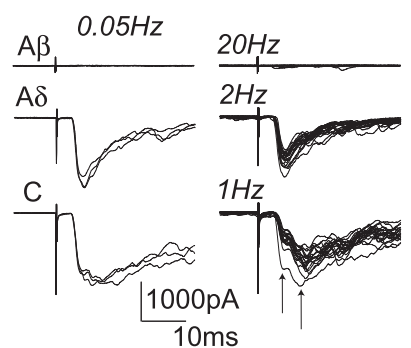

monosynaptic $A \delta+$ monosynaptic $\mathrm{C}$

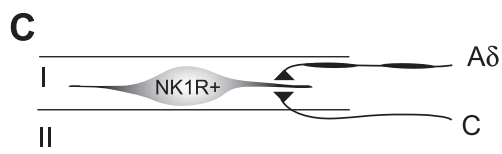

\section{Lamina I NK1R-}

(i)

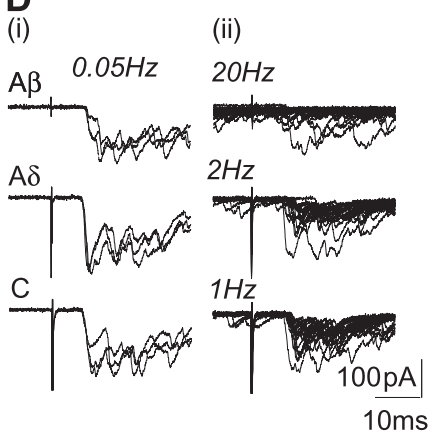

E

polysynaptic $A \beta+$ polysynaptic $A \delta$

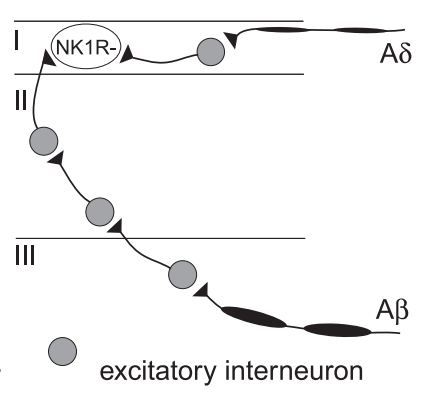

\section{$A \beta$}

Table 1. Description of primary afferent input to lamina I and III NK1R + neurons and lamina I NK1R - neurons under control conditions

\begin{tabular}{lccl}
\hline & $\begin{array}{l}\text { Lamina I NK1R+ } \\
(n=21)\end{array}$ & $\begin{array}{l}\text { Lamina I NK1R- } \\
(n=6)\end{array}$ & $\begin{array}{l}\text { Lamina III NK1R+ } \\
(n=10)\end{array}$ \\
\hline Monosynaptic A $\beta$ & $1(5 \%)$ & & $\mathbf{7 ( 7 0 \% )}$ \\
Polysynaptic $A \beta$ & $4(19 \%)$ & $3(50 \%)$ & $1(10 \%)$ \\
Monosynaptic A $\delta$ & $6(29 \%)$ & $1(17 \%)$ & $5(50 \%)$ \\
Polysynaptic A $\delta$ & $8(38 \%)$ & $\mathbf{5 ( 8 3 \% )}$ & $1(10 \%)$ \\
Monosynaptic C & $\mathbf{1 1 ( 5 2 \% )}$ & & $3(30 \%)$ \\
Polysynaptic C & $3(14 \%)$ & $2(33 \%)$ & \\
\hline
\end{tabular}

The most dominant input for each group is shown in bold.

$\mathrm{NK} 1 \mathrm{R}+$ neurons and is summarized and illustrated in Table 1 and Figure 2E, respectively.

In sharp contrast to both lamina I NK1R + and NK1R - neurons, lamina III NK1R + neurons $(n=10)$ received mainly lowthreshold $\mathrm{A} \beta$ fiber input that was monosynaptic in nature ( 7 of 10 ). Figure $2 F$ shows a typical example of EPSCs recorded from a lamina III NK1R + neuron receiving monosynaptic $A \beta$ fiber input. Dorsal root stimulation clearly evoked a response when stimulated at $25 \mu \mathrm{A}, \mathrm{A} \beta$ fiber stimulation intensity (Fig. $2 \mathrm{Fi}$ ). The EPSC could be reliably evoked at high-frequency stimulation $(20 \mathrm{~Hz})$, showing little variability in latency ( $<2 \mathrm{~ms})$ (Fig. 2 Fii). Stimulation of the dorsal root at higher intensities $(100 \mu \mathrm{A}, 500$ $\mu \mathrm{A})$ did not reveal obvious additional monosynaptic $\mathrm{A} \delta$ or $\mathrm{C}$ fiber components, although there was some increase in response magnitude. Most lamina III, NK1R + neurons with monosynaptic $\mathrm{A} \beta$ fiber input showed some evidence of additional highthreshold components that were polysynaptic $\mathrm{A} \delta$ ( 3 of 7 ) or C (3 of 7) in nature. The primary afferent input to lamina III NK1R+ neurons is summarized in Table 1, and the major input is illustrated in Figure 2G.

Disinhibition reveals novel and enhanced responses to $A$ fiber input that are predominantly $\mathrm{A} \beta$ fiber mediated in lamina I NK1R+ neurons

To determine the consequences of disinhibition on primary afferent input to lamina I NK1R + neurons, a synaptic responsestimulus intensity profile was generated for each neuron under control conditions then in the presence of the $\mathrm{GABA}_{\mathrm{A}}$ and glycine receptor antagonists bicuculline $(10 \mu \mathrm{M})$ and strychnine (300 nM) (Jonas et al., 1998). Specifically, the dorsal root was stimulated over a range of intensities $(4,8,12,25,50,100$, and $500 \mu \mathrm{A})$ to ensure systematic activation of $\mathrm{A} \beta, \mathrm{A} \delta$, and $\mathrm{C}$ fibers (Nakatsuka et al., 2000). Figure $3 A$ displays data obtained from a lamina $\mathrm{I} \mathrm{NK} 1 \mathrm{R}+$ neuron that received monosynaptic $\mathrm{C}$ fiber input. The data in Figure $3 A(i, i i)$ demonstrate that dorsal root stimulation at $\mathrm{A} \beta$ and $\mathrm{A} \delta$ intensities, which generated negligible or small EPSCs under control conditions, clearly evoked a robust response in the absence of inhibitory control.

To quantify this observation, the synaptic response-stimulus intensity profile was generated by measuring the EPSC area (900 $\mathrm{ms}$ after stimulus artifact) evoked at each stimulation intensity

$\leftarrow$

monosynaptic $A \delta$ and monosynaptic C components. C, Schematic illustrating that lamina $\mathrm{NK1R}+$ neurons predominantly receive high-threshold (C or A $\delta$ fiber) primary afferent monosynaptic input. $\boldsymbol{D}$, Characterization of primary afferent synaptic input to an individual lamina I NK1R - neuron receiving polysynaptic $A \beta$ and $A \delta$ fiber input. $\boldsymbol{E}$, Schematic illustrating that lamina I NK1R - neurons mainly receive polysynaptic $A$ fiber primary afferent input. $\boldsymbol{F}$, Characterization of primary afferent synaptic input to an individual lamina III NK1R + neuron receiving monosynaptic $A \beta$ fiber input. $\mathbf{G}$, Schematic illustrating that lamina III NK1R + neurons predominantly receive low-threshold $A \beta$ fiber primary afferent monosynaptic input.

Figure 2. Differential primary afferent synaptic input to lamina I NK1R +, lamina I NK1R-, and lamina III NK1R + neurons. $\boldsymbol{A}$ and $\boldsymbol{B}$ show characterization of primary afferent synaptic input to two lamina I NK1R + neurons receiving monosynaptic $C$ and monosynaptic $A \delta$ and $C$ fiber input, respectively. In this and subsequent panels, $i$ shows examples of EPSCs evoked by stimulation (0.1 ms) using $A \beta(25 \mu \mathrm{A}), A \delta(100 \mu \mathrm{A})$, and ( fiber $(500 \mu \mathrm{A})$ stimulation intensities at low frequency. Each trace comprises three superimposed traces evoked at $0.05 \mathrm{~Hz}$. ii shows examples of EPSCs evoked by higher-frequency stimulation $(25 \mu \mathrm{A} / 20 \mathrm{~Hz} ; 100 \mu \mathrm{A} / 2 \mathrm{~Hz}$; $500 \mu \mathrm{A} / 1 \mathrm{~Hz})$. Each trace comprises 20 superimposed traces. In $\boldsymbol{B}$, the two arrows denote the 
A

(i) control

(ii) bicuculline $(10 \mu \mathrm{M})+$ strychnine (300nM)

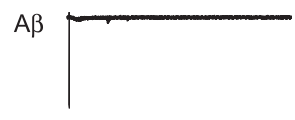

A $\delta$
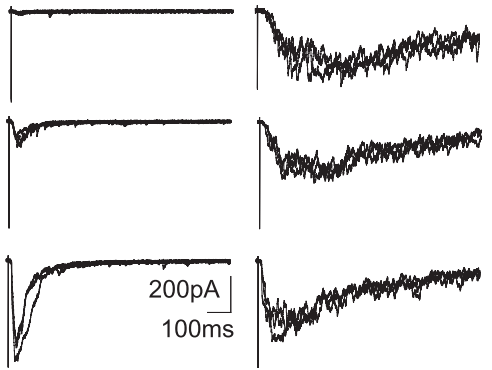

B (i)

(ii)

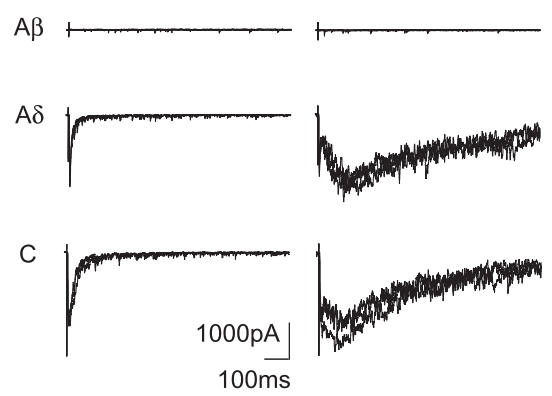

$\mathbf{C}_{(i)}$

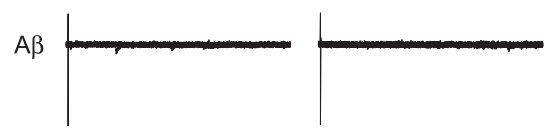

$\mathrm{A} \delta$

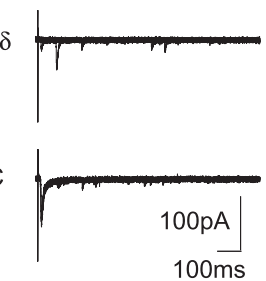

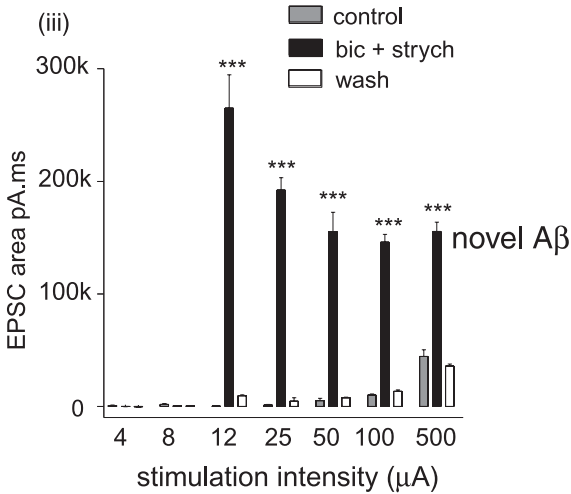

(iii)

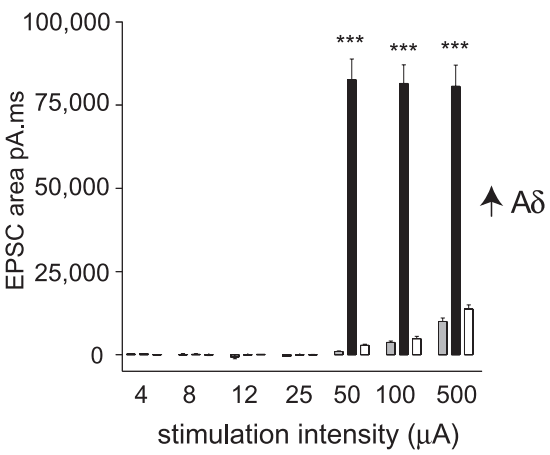

(iii)

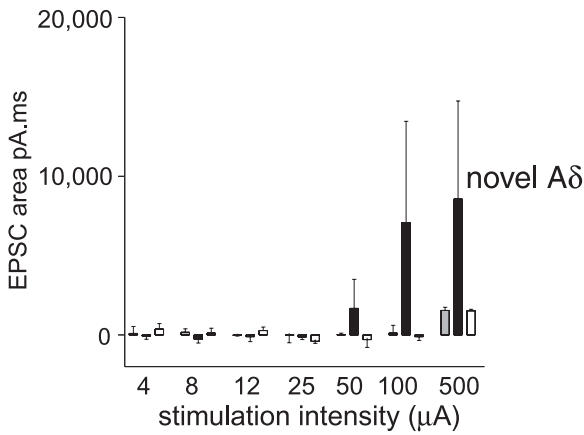

Figure 3. Disinhibition elicits novel and enhanced responses to $A$ fiber stimulation in lamina I NK1R + neurons. $\boldsymbol{A}-\boldsymbol{C}$, Data obtained from individual lamina I NK1R+ neurons with monosynaptic $($ fiber $(\boldsymbol{A}, \boldsymbol{C})$ and monosynaptic $A \delta$ fiber $(\boldsymbol{B})$ input. Disinhibition reveals $A \beta(\boldsymbol{A})$ and $A \delta(\boldsymbol{B}, \boldsymbol{C})$ fiber input. $\boldsymbol{i}$ shows examples of EPSCs evoked by stimulation ( $0.1 \mathrm{~ms})$ using $A \beta$ ( 25 $\mu \mathrm{A}), \mathrm{A} \delta(100 \mu \mathrm{A})$, and $($ fiber $(500 \mu \mathrm{A})$ stimulation intensities at low frequency under control conditions. Each trace comprises three superimposed traces evoked at $0.05 \mathrm{~Hz}$. ii shows EPSCs evoked by the same stimulation protocol as in $i$ but in the presence of bicuculline $(10 \mu \mathrm{m})$ and strychnine ( $300 \mathrm{~nm})$. iii displays the synaptic response-stimulus intensity profile generated by calculating the EPSC area from the stimulus artifact to the end of the trace $(900 \mathrm{~ms})$ for each of the three EPSC , at each intensity tested, and for all conditions. All averaged data are represented as mean \pm SE. Repeated-measures ANOVA followed by Newman-Keuls posttests were used to determine whether "bicuculline + strychnine" is significantly different from all other conditions $\left({ }^{* * *} p<\right.$ 0.001).

tested under control conditions, then in the presence of $10 \mu \mathrm{M}$ bicuculline and $300 \mathrm{~nm}$ strychnine (10 min after initial bath application) and again after a 20 min washout. These data are displayed graphically in Figure 3Aiii and show that bicuculline and strychnine significantly increase the EPSC area from stimulation intensities as low as $12 \mu \mathrm{A}$. Interestingly, the novel response evoked by $\mathrm{A} \beta$ fiber stimulation in the presence of bicuculline and strychnine far exceeded that evoked by highthreshold C fiber stimulation under control conditions. This enhanced response at lower stimulation intensities is completely reversible after washout. Therefore, this lamina I NK1R + neuron that normally received exclusively high-threshold input was found to receive novel low-threshold $\mathrm{A} \beta$ fiber input when inhibition was blocked.

Disinhibition significantly altered the response profile of 19 of 21 lamina I NK1R + neurons tested. This was because of novel or enhanced responses to A fiber input that were $A \beta$ fiber mediated in the majority of cases (14 of 19). In all cases, disinhibition induced effects were reversible after washout. In 6 of the 14 neurons where disinhibition significantly increased the EPSC area in the A $\beta$ fiber range, the response evoked by low-threshold stimulation in the presence of the inhibitory blockers was more than two SDs greater than the response elicited by highthreshold stimuli under control conditions, as observed in Figure 3A.

In some neurons ( 6 of 21), disinhibition resulted in novel or enhanced responses to $A \delta$ fiber stimulation. Figure $3 B$ displays data from one such neuron with monosynaptic $\mathrm{A} \delta$ fiber input that showed significantly increased responses to $\mathrm{A} \delta$ fiber stimulation in the presence of bicuculline and strychnine.

In 5 of the 19 neurons, disinhibition resulted in a novel response to the first stimulus but not the second and third in the train of three stimuli delivered at low frequency (Fig. 3C). This novel response was effectively lost when EPSC area was averaged across trials to generate the synaptic response-stimulus intensity profile. However, disinhibition clearly revealed an evoked response, in this case, at $\mathrm{A} \delta$ fiber stimulation intensity that was not evident under control conditions. This was therefore accepted as a significant result because the EPSC area of the first response was more than two SDs greater than the mean EPSC area under control conditions.

\section{Disinhibition revealed A fiber input onto lamina I NK1R + neurons is polysynaptic in nature}

To determine whether the A fiber input revealed by blockade of inhibitory synapses was monosynaptic or polysynaptic, responses to both low- and high-frequency stimulation were obtained in both control and disinhibited conditions. Figure $4 \mathrm{~A}$ shows data obtained from a neuron that had monosynaptic $\mathrm{C}$ fiber input but negligible $A \beta$ or $A \delta$ fiber input under control conditions. Disinhibition revealed EPSCs evoked after stimulation intensities in the $A \beta$ range, as can be seen by comparing Figure $4, A i$ and $B i$. Figure $4 B i$ shows that the low-threshold input revealed by disinhibition has a longer latency than the $\mathrm{C}$ fiber monosynaptic input. Considering the faster conduction velocity of myelinated versus unmyelinated fibers, the longer latency of 
the $\mathrm{A} \beta$ fiber mediated component is particularly striking and emphasizes its polysynaptic nature. Consistent with that interpretation are the failures and substantial variability of latency recorded at highstimulation frequencies (Fig. $4 \mathrm{Bii}$ ). Thus, the disinhibition revealed $\mathrm{A} \beta$ fiber input was polysynaptic in nature.

Notably, in all lamina I NK1R+ neurons, the novel or enhanced A fiber input revealed in the presence of bicuculline and strychnine was polysynaptic in nature. High-frequency stimulation of the dorsal root during disinhibition produced EPSCs with synaptic failures in nearly all neurons with novel or enhanced input (17 of 19) and also substantial latency variability (latency variability ranged from 6.55 to 28.44 $\mathrm{ms})$. Furthermore, in the majority of neurons (13 of 19), the synaptic input revealed during disinhibition had a longer latency than the control input, further emphasizing its polysynaptic nature. The results are summarized graphically in Figure $4 C$. The most common effect was the appearance of novel low-threshold polysynaptic $A \beta$ fiber input, as illustrated in Figure $4 D$ (for control comparison, see Fig. 2C). However, enhanced polysynaptic $\mathrm{A} \beta$ fiber input, as well as novel or enhanced polysynaptic $\mathrm{A} \delta$ fiber input, were also observed.

\section{A fiber input onto lamina I NK1R+ neurons revealed by disinhibition is NMDA receptor dependent}

Polysynaptic relays in the dorsal horn have been shown previously to involve NMDA receptor activity (Davies and Watkins, 1983; Yoshimura and Jessell, 1990). Furthermore, the NMDA receptor is clearly implicated in disinhibition-induced allodynia (Yaksh, 1989) and central components of pathophysiological pain (for review, see Lewin et al., 2004). Therefore, we sought to determine whether the polysynaptic A fiber input onto lamina I NK1R+ neurons, revealed in the absence of inhibition, was reliant on NMDA receptor activity.

Figure $5 \mathrm{~A}$ shows some example traces from a neuron, which had monosynaptic $\mathrm{C}$ and polysynaptic $\mathrm{A} \delta$ fiber input, that showed novel $\mathrm{A} \beta$ fiber input when inhibition was blocked. In the presence of bicuculline and strychnine, the novel $A \beta$ fiber input evoked response is again shown to have a longer latency than the control monosynaptic $\mathrm{C}$ fiber input, indicative of its polysynaptic nature. Furthermore, this long latency $\mathrm{A} \beta$ fiber-mediated component is abolished when bicuculline and strychnine are applied in the presence of NMDA receptor antagonist D-APV $(30 \mu \mathrm{M})$. Note that although there is a reduction in the high-threshold evoked responses in the presence of D-APV, the polysynaptic A $\delta$ or monosynaptic $\mathrm{C}$ fiber responses evoked under control conditions are not abolished. Therefore, D-APV appeared to selectively eliminate the polysynaptic activity revealed by disinhibition. Figure $5 B$ quantitatively shows that the disinhibition-induced increase in EPSC area was significantly abolished when bicuculline

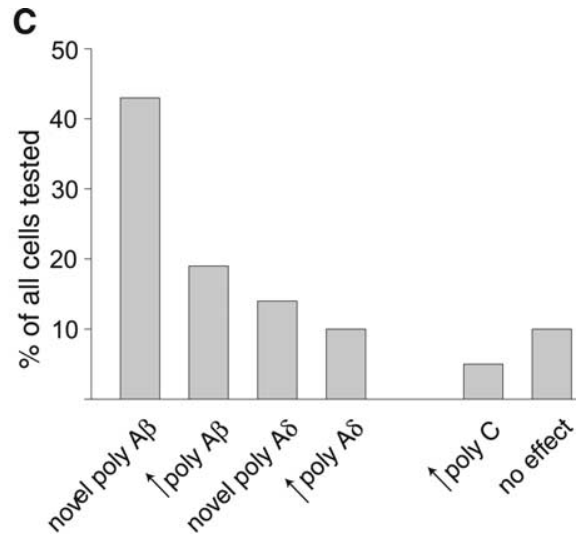

D

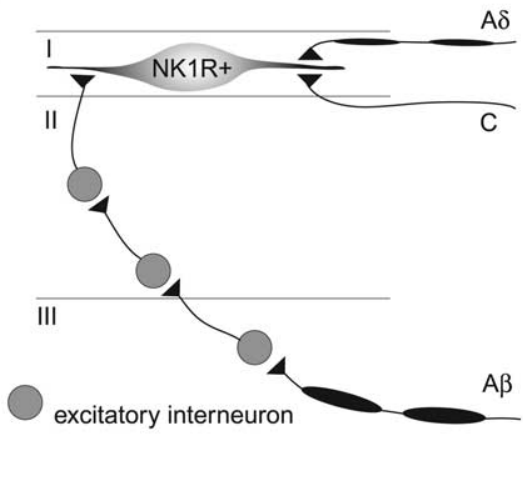

Figure 4. Novel A fiber input to lamina INK1R + neurons revealed by disinhibition is polysynaptic. $A$ and $\boldsymbol{B}$ show data obtained from a neuron with monosynaptic $C$ fiber input that received novel polysynaptic $A \beta$ fiber input when inhibition was blocked.

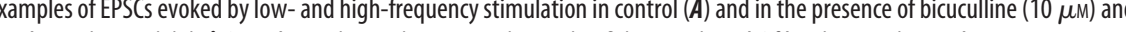
in $\boldsymbol{B}$ illustrates that the synaptic events revealed at $25 \mu \mathrm{A}$ have a longer latency than the control monosynaptic input. C, Summary of the percentage of total lamina I NK1R + neurons $(n=21)$ receiving novel or enhanced polysynaptic (poly) input, for each fibe type, under conditions of disinhibition. $\boldsymbol{D}$, Schematic illustrating the main effect of disinhibition in lamina I NK1R + neurons, which is the appearance of novel polysynaptic $A \beta$ fiber input.

and strychnine were applied in the presence of the NMDA receptor antagonist D-APV.

D-APV completely abolished the increase in EPSC area in the synaptic response-stimulus intensity profile at all stimulation intensities where disinhibition effects were observed and in all neurons tested $(n=5)$. D-APV consistently reversed the effect of bicuculline and strychnine but did not abolish control monosynaptic input. However, D-APV generally reduced control input, but this was not extensively analyzed in the present study. This is consistent with an NMDA receptor contribution to evoked EPSCs in similarly identified lamina I NKR+ neurons (C. K. Tong, unpublished observation) and also C fiber-evoked EPSCs in lamina I projection neurons (Dahlhaus et al., 2005).

Synaptic activation of NMDA receptors alone has been shown to be capable of driving action potential firing in dorsal horn neurons (Bardoni et al., 2000). Therefore, we sought to determine whether the polysynaptic A fiber input revealed by disinhibition that was blocked by NMDA receptor antagonist could function in the absence of AMPAR coactivation. Figure $5 C$ shows some example traces from a neuron shown to have increased $A \delta$ fiber-mediated responses in bicuculline and strychnine (same as in Fig. $3 B$ ). The traces are displayed at a fast time base and show 
A
(i) control
(ii) bic + strych
(iii) APV + bic + strych

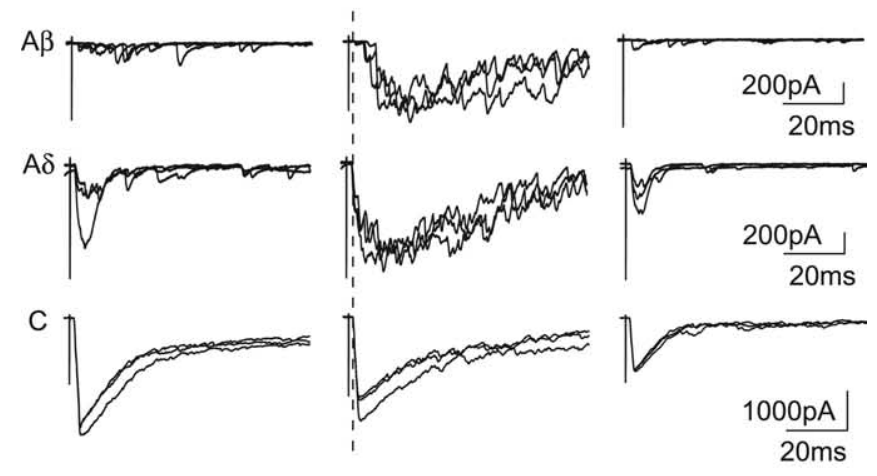

B

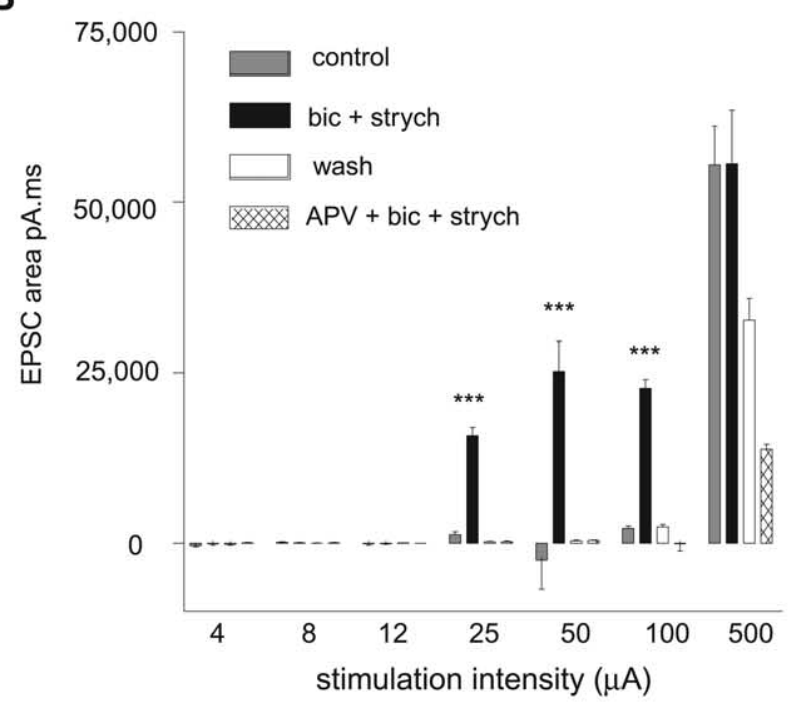

C
(i) control
(ii) bic + strych

$\mathrm{A} \delta$
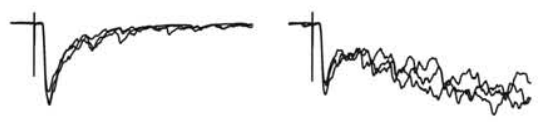

(iii) NBQX

(iv) $\mathrm{NBQX}+$ bic + strych

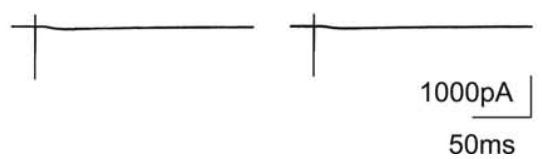

Figure 5. Disinhibition revealed polysynaptic A fiber input to lamina I NK1R + neurons is NMDA receptor dependent. $\boldsymbol{A}$ and $\boldsymbol{B}$ display data from a neuron with C fiber monosynaptic input, which demonstrates polysynaptic $A \beta$ fiber input revealed during disinhibition that is blocked by $\mathrm{D}-\mathrm{APV}$. $\boldsymbol{A i}$, Examples of EPSCs evoked by stimulation ( $0.1 \mathrm{~ms})$ using $\mathrm{A} \beta(25 \mu \mathrm{A}), \mathrm{A} \delta(100$ $\mu \mathrm{A})$, and ( fiber $(500 \mu \mathrm{A})$ stimulation intensities at low frequency under control conditions. Each trace comprises three superimposed traces evoked at $0.05 \mathrm{~Hz}$.ii shows EPSCs evoked by the same stimulation protocol but in the presence of bicuculline $(10 \mu \mathrm{M})$ and strychnine $(300 \mathrm{nM})$, and again in iii in the presence of bicuculline (10 $\mu \mathrm{m})$, strychnine (300 nM), and D-APV $(30 \mu \mathrm{M})$. Note that the synaptic events revealed at $A \beta$ intensity have a longer latency than the control monosynaptic input (dotted line). $\boldsymbol{B}$, The synaptic response-stimulus intensity profile generated by calculating the EPSC area from the stimulus artifact to the end of the recording $(900 \mathrm{~ms})$ for each of the three EPSCs at each intensity tested and for all conditions. C, Data from a neuron with control monosynaptic $A \delta$ fiber input and disinhibition revealed polysynaptic $A \delta$ fiber input, both of which are abolished, in the presence of NBQX. EPSCs evoked by low-frequency that the synaptic component revealed by disinhibition begins on the falling phase of the control monosynaptic EPSC evoked by A $\delta$ fiber stimulation. The longer latency is again indicative of its polysynaptic nature. When NBQX $(10 \mu \mathrm{M})$ alone is applied, the control monosynaptic input is essentially blocked. When bicuculline and strychnine are applied together with NBQX, dorsal root stimulation still did not result in any evoked response. In four of five neurons tested, NBQX alone virtually abolished all evoked EPSCs. When bicuculline and strychnine were applied in the presence of NBQX, no additional increase in evoked activity was observed. Therefore, the polysynaptic A fiber input revealed by disinhibition appears to be dependent, but not solely reliant on, NMDA receptor activity to be functional.

Disinhibition enhances polysynaptic A fiber input to lamina I NK1R - neurons in an NMDA receptor-dependent manner

The effects of disinhibition on primary afferent input to lamina I neurons lacking the NK1 receptor, which we have demonstrated normally receive polysynaptic $\mathrm{A} \beta$ and/or polysynaptic $\mathrm{A} \delta$ fiber input, was tested in a similar manner. Figure 6 shows data from a lamina I NK1R - neuron, which received polysynaptic $A \beta$ and A $\delta$ fiber input under control conditions. Figure $6 A$ shows that $\mathrm{A} \beta$ fiber stimulation clearly elicited a greater and longer lasting response in the presence of bicuculline and strychnine. This is summarized for all stimulation intensities in the synaptic response-stimulus intensity profile (Fig. $6 \mathrm{C}$ ) and is shown to be reversible. Figure $6 B$ shows traces (at a much faster timescale than in Fig. 6A) evoked by high-frequency stimulation at $\mathrm{A} \beta$ fiber intensity. In control conditions (Fig. $6 \mathrm{Bi}$ ), high-frequency stimulation resulted in failures indicating that the $A \beta$ fiber input is polysynaptic. In the presence of bicuculline and strychnine (Fig. 6 Bii), high-frequency stimulation also generated failures demonstrating that "polysynaptic" input also underlies the disinhibition enhanced response. The shifting baseline in Figure 6 Bii reflects the increased response in bicuculline and strychnine (Fig. 6Aii) that has not returned to baseline before the next stimulus in the high-frequency train $(50 \mathrm{~ms}$ intervals at $20 \mathrm{~Hz})$.

In most lamina I NK1R - neurons tested (5 of 6 ), disinhibition significantly and reversibly enhanced polysynaptic $\mathrm{A} \beta$ and/or polysynaptic $A \delta$ fiber input and is illustrated in Figure $6 D$ (for control comparison, see Fig. 2E). Notably, in contrast to lamina I NK1R + neurons, disinhibition did not reveal novel low-threshold input to any neuron with exclusively highthreshold input. The synaptic response-stimulus intensity profile (Fig. 6C) also demonstrates that the disinhibition revealed polysynaptic input is significantly abolished when bicuculline and strychnine are applied in the presence of D-APV. Thus disinhibition-induced increases in polysynaptic $\mathrm{A}$ fiber input to lamina I NK1R - neurons is NMDA receptor dependent $(n=3)$.

These results are entirely consistent with the NMDA receptordependent facilitation of $A \beta$ and $A \delta$ fiber polysynaptic input to unidentified superficial dorsal horn neurons with preexisting $\mathrm{A} \beta$ and $\mathrm{A} \delta$ fiber input (Baba et al., 2003). Interestingly, the study by Baba et al. (2003) was performed in adult rats (8-10 weeks of age), suggesting that the results obtained in the present study, in $\sim 3$-week-old rats, are not limited to a more immature system.

$\leftarrow$

stimulation $(0.1 \mathrm{~ms}, 0.05 \mathrm{~Hz})$ using $\mathrm{A} \delta$ fiber stimulation intensity $(100 \mu \mathrm{A})$ under control conditions (i), in $10 \mu \mathrm{m}$ bicuculline and $300 \mathrm{~nm}$ strychnine (ii), in $10 \mu \mathrm{M}$ NBQX (iii), in $10 \mu \mathrm{M}$ bicuculline, $300 \mathrm{~nm}$ strychnine, and $10 \mu \mathrm{m}$ NBQX (iv). Each trace comprises three superimposed traces evoked at $0.05 \mathrm{~Hz}$. 
A (i) control

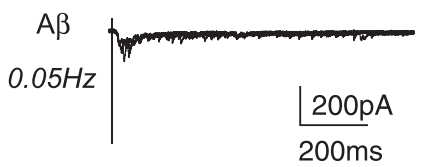

B

(i)

$2 \mathrm{OHz}$

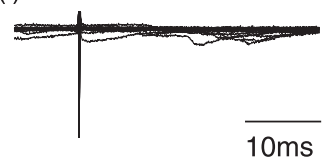

(ii) bic + strych

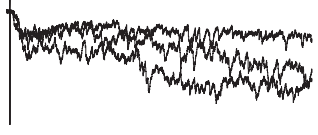

(ii)

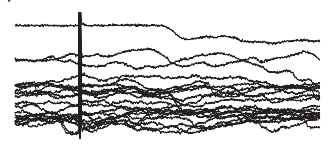

C

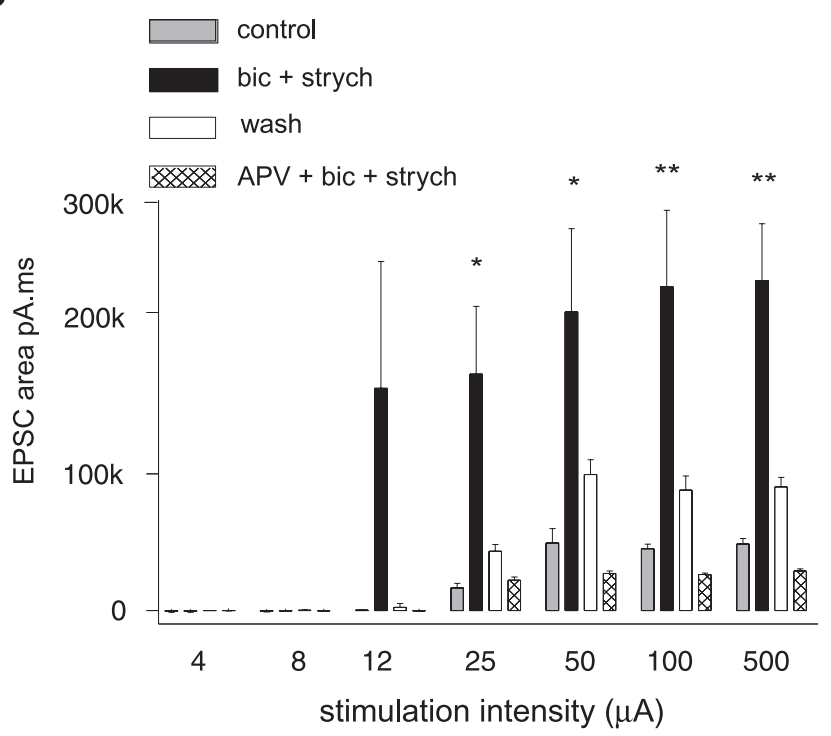

D

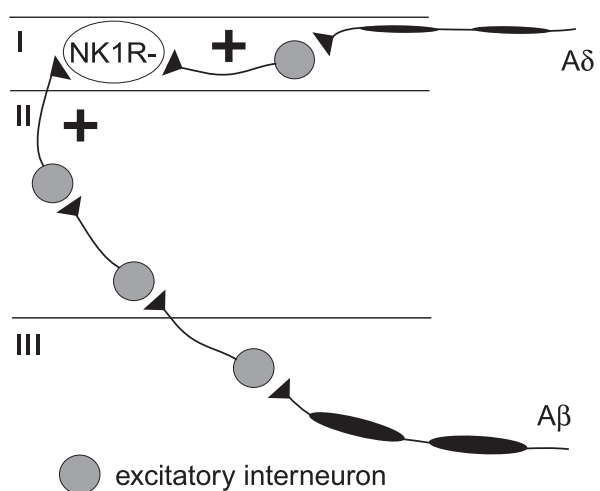

Figure 6. Disinhibition increases polysynaptic A fiber input to lamina INK1R - neurons in an NMDA receptor-dependent manner. Data are from a neuron with polysynaptic $A \beta$ and $A \delta$ fiber input, which shows increased polysynaptic A fiber input during disinhibition that is blocked by D-APV. Ai shows examples of EPSCs evoked by stimulation $(0.1 \mathrm{~ms})$ using $A \beta(25 \mu \mathrm{A})$ stimulation intensities at low frequency under control conditions. Each trace comprises three superimposed traces evoked at $0.05 \mathrm{~Hz}$. ii shows EPSCs evoked by the same stimulation protocol as in $\boldsymbol{i}$ but in the presence of bicuculline $(10 \mu \mathrm{M})$ and strychnine $(300 \mathrm{~nm})$. B, EPSCs evoked by higherfrequency stimulation ( $20 \mathrm{~Hz})$ at $\mathrm{A} \beta(25 \mu \mathrm{A})$ stimulation intensities in control $(\boldsymbol{i})$ and disinhibition (ii) conditions at a faster timescale. Each trace comprises 20 superimposed traces. C, The synaptic response-stimulus intensity profile generated by calculating the EPSC area from the stimulus artifact to the end of the trace $(900 \mathrm{~ms})$ for each of the three EPSCS, at each intensity tested, and for all conditions. D, Schematic illustrating that disinhibition enhances polysynaptic A fiber input to lamina I NK1R - neurons.
Disinhibition enhances dorsal root evoked responses in lamina III NK1R + neurons in an NMDA

\section{receptor-dependent manner}

The effects of disinhibition on the dorsal root-evoked responses of lamina III NK1R + neurons, which we have shown to normally receive mainly low-threshold $A \beta$ fiber monosynaptic input, were also tested. Figure 7 shows that disinhibition caused enhancement of dorsal root evoked responses at all intensities tested. In most neurons tested ( 9 of 10), disinhibition significantly augmented EPSC area in the synaptic response-stimulus intensity profile and this effect was reversed after washout. EPSC area was significantly increased from intensities in the $A \beta$ range in the majority of neurons (six of nine) but not until the A $\delta$ fiber range in the remainder (three of nine). Notably, unlike lamina I $\mathrm{NK} 1 \mathrm{R}+$ neurons, disinhibition did not lower the threshold stimulation intensity required to evoke EPSCs in any lamina III neuron tested.

All lamina III NK1R + neurons were tested using both lowand high-frequency dorsal root stimulation under control and disinhibition conditions in an attempt to determine the basis for the enhanced EPSCs observed in the absence of inhibition. However, given that the disinhibition effect was superimposed on a control short-latency monosynaptic $\mathrm{A} \beta$ fiber input, this approach was not informative about the underlying nature of the disinhibition-enhanced response (data not shown).

Interestingly, Figure 7, Aiii and B, illustrates that D-APV significantly blocked the disinhibition augmented EPSCs at all intensities observed in that example. In fact, D-APV, which blocked disinhibition revealed polysynaptic A fiber input to lamina I $\mathrm{NK} 1 \mathrm{R}+$ and lamina NK1R - neurons, significantly reversed all bicuculline and strychnine induced increases in EPSC area in all lamina III NK1R + neurons tested $(n=5)$. This is consistent with an interpretation that the activity revealed by disinhibition may be polysynaptic in nature and is illustrated in Figure $7 C$ (for control comparison, see Fig. 2G).

\section{Discussion}

We found that the primary afferent drive onto lamina I and III $\mathrm{NK} 1 \mathrm{R}+$ and lamina I NK1R - neurons was strikingly different. Primary afferent monosynaptic input onto lamina I NK1R+ neurons was predominantly high threshold $(\mathrm{A} \delta / \mathrm{C})$, whereas most lamina III NK1R+ neurons received monosynaptic lowthreshold $(\mathrm{A} \beta)$ input. In contrast, lamina I NKIR - neurons received polysynaptic A fiber input. In the absence of inhibitory control, a powerful NMDA receptor-dependent polysynaptic A fiber input onto lamina I NK1R + neurons was revealed. In most cases, the revealed input was driven by low-threshold $\mathrm{A} \beta$ fibers, potentially transforming "nociceptive-specific" neurons into "wide dynamic range" neurons. In both lamina I NK1R - and lamina III NK1R+ neurons, disinhibition enhanced evoked responses to existing primary afferent input in an NMDA receptordependent manner. Pathological disruption of local spinal cord inhibition could therefore lead to the transmission of novel innocuous and enhanced nociceptive input in ascending pathways that normally mediate pain sensation and thereby contribute to chronic pain hypersensitivity.

\section{Primary afferent input}

Lamina I neurons expressing NK1 receptors receive discrete synaptic contacts from one or more primary afferent fiber types (Hwang et al., 2003), including substance P-containing afferents (Todd et al., 2002; Hwang et al., 2003) that comprise both A $\delta$ and C fiber types (Lawson et al., 1997). Functionally, it has been 
A

(i) control
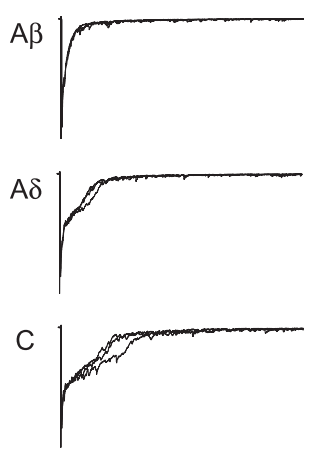

(ii) bic + strych

(iii) APV + bic + strych
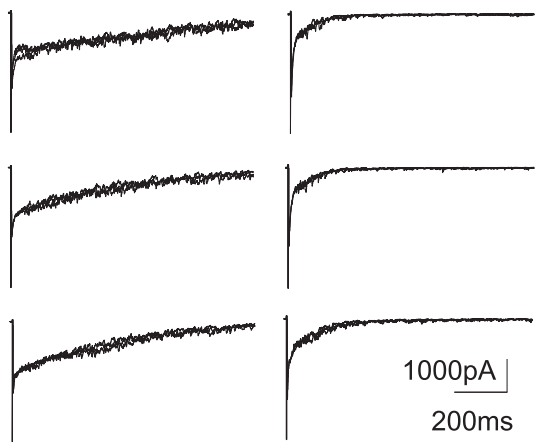

B

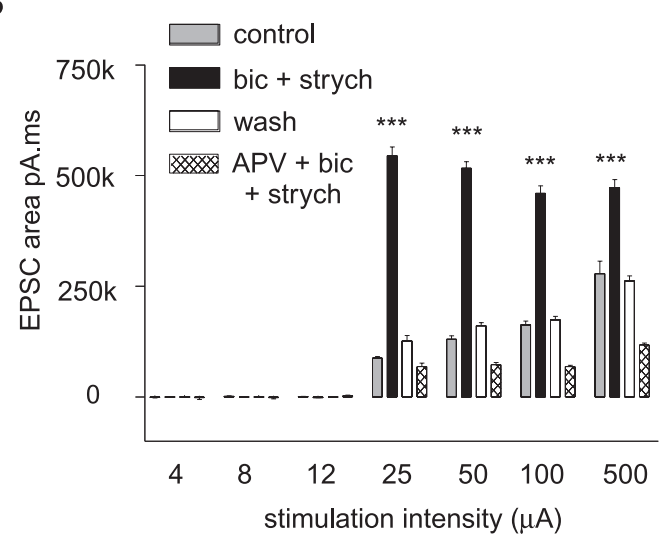

C

I

II

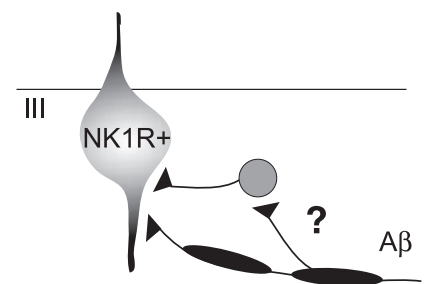

Figure 7. Disinhibition enhances responses to A fiber input in lamina III NK1R + neurons and is blocked by an NMDA receptor antagonist. These data are from the neuron shown to receive monosynaptic $A \beta$ fiber input in Figure $2 F$ and are shown at a slower timescale. Ai shows examples of EPSCs evoked by stimulation ( $0.1 \mathrm{~ms})$ using $A \beta(25 \mu \mathrm{A}), A \delta(100 \mu \mathrm{A})$, and ( fiber $(500 \mu \mathrm{A})$ stimulation intensities at low frequency under control conditions. Each trace comprises three superimposed traces evoked at $0.05 \mathrm{~Hz}$. ii shows EPSCs evoked by the same stimulation protocol as in $i$ but in the presence of bicuculline $(10 \mu \mathrm{M})$ and strychnine ( $300 \mathrm{~nm})$, and, in iii, in the presence of bicuculline (10 $\mu \mathrm{m})$, strychnine (300 nм), and D-APV (30 $\mu \mathrm{M})$. $\boldsymbol{B}$, The synaptic response-stimulus intensity profile generated by calculating the EPSC area from the stimulus artifact to the end of the trace $(900 \mathrm{~ms})$ for each of the three EPSCs, at each intensity tested, and for all conditions. C, Schematic illustrating that polysynaptic A fiber input may underlie the disinhibition enhanced evoked responses in lamina III NK1R + neurons.

shown that lamina I neurons that depolarize in response to NK1 receptor agonist, and thus express NK1 receptor, receive $\mathrm{C}$ fiber input (Cheunsuang et al., 2002). Furthermore, few unidentified lamina I but many lamina I projection neurons receive $\mathrm{C}$ fiber monosynaptic input (Ruscheweyh et al., 2004). This is consistent with the present demonstration that lamina I NK1R + neurons receive monosynaptic high-threshold $(\mathrm{C}>\mathrm{A} \delta)$ input, whereas lamina I NK1R - neurons are dominated by polysynaptic input.

Lamina I neurons expressing NK1 receptors project to the thalamus (Marshall et al., 1996) and several brainstem sites including a strong projection to the parabrachial area (Ding et al., 1995; Todd et al., 2000; Spike et al., 2003). NK1 receptor immunoreactive spinoparabrachial neurons upregulate Fos in response to noxious stimuli (Todd et al., 2002, 2005), and electrophysiological studies demonstrate that lamina I spinoparabrachial neurons are nociceptive specific (Bester et al., 2000).

Lamina III/IV neurons expressing NK1 receptors can be thought of as two morphologically and functionally different groups. One group includes neurons with long dorsally directed dendrites that extend through lamina I/II (Bleazard et al., 1994; Brown et al., 1995; Littlewood et al., 1995). Morphologically, they receive limited myelinated afferent input as well as dense innervation from substance P-containing primary afferents in lamina I/II. They have been likened to wide dynamic range neurons (Naim et al., 1997, 1998) and project to the brainstem (Todd et al., 2000) and thalamus (Marshall et al., 1996). The other subgroup of lamina III/IV, NK1R+ neurons have more restricted dendritic trees. The function of these neurons is unclear because they do not show Fos expression or NK1 receptor internalization after noxious stimulation (Mantyh et al., 1995; Doyle and Hunt, 1999). In our studies, $70 \%$ of these NK1R+ neurons received only low-threshold, $\mathrm{A} \beta$ fiber monosynaptic input but not highthreshold monosynaptic input associated with nociception, Fos expression, and NK1 receptor internalization. This may suggest that the majority of lamina III NK1R + neurons tested belong to the second category of neurons with more restricted dendritic trees.

The occurrence of evoked high-threshold monosynaptic input in NK1R + lamina III neurons (20\% of neurons; 2 of 10) was less common than the occurrence of capsaicin-induced increase in frequency of miniature EPSCs recorded in similarly preidentified neurons (43\% of TMR-SP-labeled lamina III neurons) (Labrakakis and MacDermott, 2003). Response to capsaicin indicates that this subset of lamina III NK1R + neurons receive direct synaptic input from capsaicin sensitive nociceptors. It may be that in our experiments with dorsal root evoked synaptic input, we mainly recorded from the neuron population with restricted dendritic trees. Alternatively, we recorded from lamina III neurons with dorsally directed dendrites, but the afferent input and/or dendritic tree was not retained fully intact in the slice preparation. In any case, we clearly demonstrate a strong functional monosynaptic $\mathrm{A} \beta$ fiber input to lamina III NK1R+ neurons (not previously demonstrated). During chronic inflammation, this monosynaptic $A \beta$ fiber input may contribute to NK1 receptor internalization observed in lamina III/IV NK1R+ neurons after non-noxious stimulation (Abbadie et al., 1997), when $\mathrm{A} \beta$ fibers show novel expression of substance $\mathrm{P}$ (Neumann et al., 1996).

\section{Disinhibition revealed input}

Disinhibition dynamically alters transmission of sensory input through the lamina I pain pathway. Most striking was the substantial, long-lasting polysynaptic activity generated by lowthreshold, $\mathrm{A} \beta$ fiber stimulation in lamina I NK1R + neurons that was revealed by disinhibition. This novel input differs from the facilitation of preexisting A fiber input to lamina I NK1R - neurons (Fig. 6) and unidentified superficial dorsal horn neurons 
(Baba et al., 2003). Similarly, bicuculline facilitates A $\delta$ fiberevoked action potential firing in rat lamina I neurons in vivo (Seagrove et al., 2004). The contrasting observation that disinhibition revealed novel A fiber input $(\mathrm{A} \beta>\mathrm{A} \delta)$ in $>50 \%$ of lamina I NK1R + neurons tested suggests that under such conditions, low-threshold tactile stimuli could drive central nociceptive circuitry. Interestingly, these lamina I NK1R+ neurons project to brainstem regions thought to be involved in the generation of "defensive" reactions and "vocalization" (Bernard et al., 1996), the very behaviors evoked by tactile stroking stimuli in the bicuculline/strychnine allodynia model (Yaksh, 1989). Transmission of low-threshold, $\mathrm{A} \beta$ fiber input in this nociceptive-specific projection pathway may therefore contribute to the sensation of allodynia. Correspondingly, disinhibition revealed polysynaptic high-threshold input may contribute to hyperalgesia.

It is possible that some polysynaptic A fiber activity is driven by the small subset of $\mathrm{A} \beta$ fibers that are nociceptors or $\mathrm{A} \delta$ fibers that innervate down hairs (Djouhri and Lawson, 2004). This would still result in either increased nociceptive or novel innocuous transmission in the lamina I pain pathway. Disinhibition enhanced responses of lamina III NK1R+ neurons could similarly contribute to augmented transmission in ascending sensory pathways.

\section{Role of NMDA receptor}

The proposed circuit underlying low-threshold activation of lamina I neurons under conditions of disinhibition is shown in supplemental Figure 1 (available at www.jneurosci.org as supplemental material). The lamina I NK1R + neuron receives highthreshold monosynaptic input and also NMDA receptordependent polysynaptic $\mathrm{A} \beta$ fiber input that is normally under strong inhibitory control. We propose that inhibitory interneurons directly act on some or all excitatory interneurons in the polysynaptic pathway. Low-threshold drive onto these excitatory interneurons has both AMPA and NMDA receptor-mediated components. By hyperpolarizing excitatory interneurons, synaptic inhibition maintains the $\mathrm{Mg}^{2+}$ block and suppresses current flow through NMDA receptors. Because the polysynaptic input is dependent on an NMDA receptor-mediated component to be functional, synaptic inhibition normally acts to suppress this polysynaptic activity. This type of inhibitory control is unlikely to be significant at the level of the lamina I NK1R + neuron, because recorded neurons were voltage clamped at $-70 \mathrm{mV}$. At this potential, current flow through the NMDA receptor should be mostly blocked.

This inhibitory control may be tonically active and/or primary afferent driven (Narikawa et al., 2000). In our proposed circuit, low-threshold afferent input drives inhibition of a polysynaptic excitatory pathway to the NK1R+ lamina I neuron that is also driven by low-threshold afferent input. However, we do not exclude an important role for nonafferent driven inhibition. Lowthreshold input drives inhibition to prevent activation of the output or lamina I NK1R + neuron by low-threshold, polysynaptic excitation, thus preventing potentially pathological pain. This is analogous to the gate control theory (Melzack and Wall, 1965), in which low-threshold afferent input centrally inhibits the responsiveness of output neurons, but in this case, to high-threshold nociceptive afferent input. Disinhibition, in our model, opens the gate allowing enhanced synaptic drive through the NMDA receptor-dependent polysynaptic pathway, dramatically altering sensory input to lamina I NK1R + neurons. Finally, activation of lamina I NK1R + neurons by novel low-threshold and enhanced nociceptive input has the potential to profoundly alter sensory processing by driving the supraspinal loop which controls spinal excitability (Suzuki et al., 2002).

Chronic pain states are thought to be established and maintained in the lamina I pain pathway (Mantyh and Hunt, 2004), and disruption of inhibitory control is a common feature of such states. There are reports of reduced dorsal horn levels of GABA and its synthesizing enzyme GAD65 (Ibuki et al., 1997; Eaton et al., 1998; Moore et al., 2002), reduced inhibitory synaptic transmission (Moore et al., 2002; Muller et al., 2003; Harvey et al., 2004; Scholz et al., 2005), and a shift in the anion gradient, which renders inhibitory events excitatory in lamina I neurons (Coull et al., 2003). In each scenario, the resultant suppression of inhibitory control or shift in anion gradient could allow NMDA receptor activation and potentially reveal the polysynaptic pathway observed in the present study. If the disinhibition-revealed, polysynaptic pathway demonstrated here contributes to allodynia/hyperalgesia in chronic pain states, elucidating the key receptor subunits involved could aid the targeting of pathological versus nociceptive pain.

\section{References}

Abbadie C, Trafton J, Liu H, Mantyh PW, Basbaum AI (1997) Inflammation increases the distribution of dorsal horn neurons that internalize the neurokinin-1 receptor in response to noxious and non-noxious stimulation. J Neurosci 17:8049-8060.

Baba H, Ji RR, Kohno T, Moore KA, Ataka T, Wakai A, Okamoto M, Woolf CJ (2003) Removal of GABAergic inhibition facilitates polysynaptic A fibermediated excitatory transmission to the superficial spinal dorsal horn. Mol Cell Neurosci 24:818-830.

Bardoni R, Magherini PC, MacDermott AB (2000) Activation of NMDA receptors drives action potentials in superficial dorsal horn from neonatal rats. NeuroReport 11:1721-1727.

Bennett VJ, Simmons MA (2001) Analysis of fluorescently labeled substance $\mathrm{P}$ analogs: binding, imaging and receptor activation. BMC Chem Biol 1:1.

Bernard JF, Bester H, Besson JM (1996) Involvement of the spinoparabrachio-amygdaloid and -hypothalamic pathways in the autonomic and affective emotional aspects of pain. Prog Brain Res 107:243-255.

Bester H, Chapman V, Besson JM, Bernard JF (2000) Physiological properties of the lamina I spinoparabrachial neurons in the rat. J Neurophysiol $83: 2239-2259$

Bleazard L, Hill RG, Morris R (1994) The correlation between the distribution of the NK1 receptor and the actions of tachykinin agonists in the dorsal horn of the rat indicates that substance $\mathrm{P}$ does not have a functional role on substantia gelatinosa (lamina II) neurons. J Neurosci 14:7655-7664.

Brown JL, Liu H, Maggio JE, Vigna SR, Mantyh PW, Basbaum AI (1995) Morphological characterization of substance $\mathrm{P}$ receptor-immunoreactive neurons in the rat spinal cord and trigeminal nucleus caudalis. J Comp Neurol 356:327-344.

Cheunsuang O, Morris R (2000) Spinal lamina I neurons that express neurokinin 1 receptors: morphological analysis. Neuroscience 97:335-345.

Cheunsuang O, Maxwell D, Morris R (2002) Spinal lamina I neurones that express neurokinin 1 receptors: II. Electrophysiological characteristics, responses to primary afferent stimulation and effects of a selective muopioid receptor agonist. Neuroscience 111:423-434.

Coull JA, Boudreau D, Bachand K, Prescott SA, Nault F, Sik A, De Koninck P, De Koninck Y (2003) Trans-synaptic shift in anion gradient in spinal lamina I neurons as a mechanism of neuropathic pain. Nature 424:938-942.

Dahlhaus A, Ruscheweyh R, Sandkuhler J (2005) Synaptic input of rat spinal lamina I projection and unidentified neurones in vitro. J Physiol (Lond) 566:355-368.

Davies J, Watkins JC (1983) Role of excitatory amino acid receptors in mono- and polysynaptic excitation in the cat spinal cord. Exp Brain Res 49:280-290.

Ding YQ, Takada M, Shigemoto R, Mizumo N (1995) Spinoparabrachial tract neurons showing substance $\mathrm{P}$ receptor-like immunoreactivity in the lumbar spinal cord of the rat. Brain Res 674:336-340. 
Djouhri L, Lawson SN (2004) Abeta-fiber nociceptive primary afferent neurons: a review of incidence and properties in relation to other afferent A-fiber neurons in mammals. Brain Res Brain Res Rev 46:131-145.

Doyle CA, Hunt SP (1999) Substance P receptor (neurokinin-1)-expressing neurons in lamina I of the spinal cord encode for the intensity of noxious stimulation: a c-Fos study in rat. Neuroscience 89:17-28.

Drew GM, Siddall PJ, Duggan AW (2004) Mechanical allodynia following contusion injury of the rat spinal cord is associated with loss of GABAergic inhibition in the dorsal horn. Pain 109:379-388.

Eaton MJ, Plunkett JA, Karmally S, Martinez MA, Montanez K (1998) Changes in GAD- and GABA-immunoreactivity in the spinal dorsal horn after peripheral nerve injury and promotion of recovery by lumbar transplant of immortalized serotonergic precursors. J Chem Neuroanat $16: 57-72$.

Fitzgerald M (2005) The development of nociceptive circuits. Nat Rev Neurosci 6:507-520.

Harvey RJ, Depner UB, Wassle H, Ahmadi S, Heindl C, Reinold H, Smart TG, Harvey K, Schutz B, Abo-Salem OM, Zimmer A, Poisbeau P, Welzl H, Wolfer DP, Betz H, Zeilhofer HU, Muller U (2004) GlyR alpha3: an essential target for spinal PGE2-mediated inflammatory pain sensitization. Science 304:884-887.

Hwang SJ, Burette A, Valtschanoff JG (2003) VR1-positive primary afferents contact NK1-positive spinoparabrachial neurons. J Comp Neurol 460:255-265.

Ibuki T, Hama AT, Wang XT, Pappas GD, Sagen J (1997) Loss of GABAimmunoreactivity in the spinal dorsal horn of rats with peripheral nerve injury and promotion of recovery by adrenal medullary grafts. Neuroscience 76:845-858.

Jonas P, Bischofberger J, Sandkuhler J (1998) Corelease of two fast neurotransmitters at a central synapse. Science 281:419-424.

Khasabov SG, Rogers SD, Ghilardi JR, Peters CM, Mantyh PW, Simone DA (2002) Spinal neurons that possess the substance P receptor are required for the development of central sensitization. J Neurosci 22:9086-9098.

Khasabov SG, Ghilardi JR, Mantyh PW, Simone DA (2005) Spinal neurons that express NK-1 receptors modulate descending controls that project through the dorsolateral funiculus. J Neurophysiol 93:998-1006.

Labrakakis C, MacDermott AB (2003) Neurokinin receptor 1-expressing spinal cord neurons in lamina I and III/IV of postnatal rats receive inputs from capsaicin sensitive fibers. Neurosci Lett 352:121-124.

Lawson SN, Crepps BA, Perl ER (1997) Relationship of substance P to afferent characteristics of dorsal root ganglion neurones in guinea-pig. J Physiol (Lond) 505:177-191.

Lewin GR, Lu Y, Park TJ (2004) A plethora of painful molecules. Curr Opin Neurobiol 14:443-449.

Littlewood NK, Todd AJ, Spike RC, Watt C, Shehab SA (1995) The types of neuron in spinal dorsal horn which possess neurokinin-1 receptors. Neuroscience 66:597-608.

Mantyh PW, Hunt SP (2004) Setting the tone: superficial dorsal horn projection neurons regulate pain sensitivity. Trends Neurosci 27:582-584.

Mantyh PW, DeMaster E, Malhotra A, Ghilardi JR, Rogers SD, Mantyh CR, Liu H, Basbaum AI, Vigna SR, Maggio JE, Simone DA (1995) Receptor endocytosis and dendrite reshaping in spinal neurons after somatosensory stimulation. Science 268:1629-1632.

Mantyh PW, Rogers SD, Honore P, Allen BJ, Ghilardi JR, Li J, Daughters RS, Lappi DA, Wiley RG, Simone DA (1997) Inhibition of hyperalgesia by ablation of lamina I spinal neurons expressing the substance P receptor. Science 278:275-279.

Marshall GE, Shehab SA, Spike RC, Todd AJ (1996) Neurokinin-1 receptors on lumbar spinothalamic neurons in the rat. Neuroscience 72:255-263.

Melzack R, Wall PD (1965) Pain mechanisms: a new theory. Science 150:971-979.

Moore KA, Kohno T, Karchewski LA, Scholz J, Baba H, Woolf CJ (2002) Partial peripheral nerve injury promotes a selective loss of GABAergic inhibition in the superficial dorsal horn of the spinal cord. J Neurosci 22:6724-6731.

Muller F, Heinke B, Sandkuhler J (2003) Reduction of glycine receptormediated miniature inhibitory postsynaptic currents in rat spinal lamina I neurons after peripheral inflammation. Neuroscience 122:799-805.
Naim M, Spike RC, Watt C, Shehab SA, Todd AJ (1997) Cells in laminae III and IV of the rat spinal cord that possess the neurokinin-1 receptor and have dorsally directed dendrites receive a major synaptic input from tachykinin-containing primary afferents. J Neurosci 17:5536-5548.

Naim MM, Shehab SA, Todd AJ (1998) Cells in laminae III and IV of the rat spinal cord which possess the neurokinin-1 receptor receive monosynaptic input from myelinated primary afferents. Eur J Neurosci 10:3012-3019.

Nakatsuka T, Ataka T, Kumamoto E, Tamaki T, Yoshimura M (2000) Alteration in synaptic inputs through C-afferent fibers to substantia gelatinosa neurons of the rat spinal dorsal horn during postnatal development. Neuroscience 99:549-556.

Narikawa K, Furue H, Kumamoto E, Yoshimura M (2000) In vivo patchclamp analysis of IPSCs evoked in rat substantia gelatinosa neurons by cutaneous mechanical stimulation. J Neurophysiol 84:2171-2174.

Neumann S, Doubell TP, Leslie T, Woolf CJ (1996) Inflammatory pain hypersensitivity mediated by phenotypic switch in myelinated primary sensory neurons. Nature 384:360-364.

Nichols ML, Allen BJ, Rogers SD, Ghilardi JR, Honore P, Luger NM, Finke MP, Li J, Lappi DA, Simone DA, Mantyh PW (1999) Transmission of chronic nociception by spinal neurons expressing the substance $\mathrm{P}$ receptor. Science 286:1558-1561.

Park JS, Nakatsuka T, Nagata K, Higashi H, Yoshimura M (1999) Reorganization of the primary afferent termination in the rat spinal dorsal horn during post-natal development. Brain Res Dev Brain Res 113:29-36.

Ruscheweyh R, Ikeda H, Heinke B, Sandkuhler J (2004) Distinctive membrane and discharge properties of rat spinal lamina I projection neurones in vitro. J Physiol (Lond) 555:527-543.

Scholz J, Broom DC, Youn DH, Mills CD, Kohno T, Suter MR, Moore KA, Decosterd I, Coggeshall RE, Woolf CJ (2005) Blocking caspase activity prevents transsynaptic neuronal apoptosis and the loss of inhibition in lamina II of the dorsal horn after peripheral nerve injury. J Neurosci 25:7317-7323.

Seagrove LC, Suzuki R, Dickenson AH (2004) Electrophysiological characterisations of rat lamina I dorsal horn neurones and the involvement of excitatory amino acid receptors. Pain 108:76-87.

Sivilotti L, Woolf CJ (1994) The contribution of $\mathrm{GABA}_{\mathrm{A}}$ and glycine receptors to central sensitization: disinhibition and touch-evoked allodynia in the spinal cord. J Neurophysiol 72:169-179.

Spike RC, Puskar Z, Andrew D, Todd AJ (2003) A quantitative and morphological study of projection neurons in lamina I of the rat lumbar spinal cord. Eur J Neurosci 18:2433-2448.

Suzuki R, Morcuende S, Webber M, Hunt SP, Dickenson AH (2002) Superficial NK1-expressing neurons control spinal excitability through activation of descending pathways. Nat Neurosci 5:1319-1326.

Todd AJ, Sullivan AC (1990) Light microscope study of the coexistence of GABA-like and glycine-like immunoreactivities in the spinal cord of the rat. J Comp Neurol 296:496-505.

Todd AJ, Spike RC, Polgar E (1998) A quantitative study of neurons which express neurokinin- 1 or somatostatin sst2a receptor in rat spinal dorsal horn. Neuroscience 85:459-473.

Todd AJ, McGill MM, Shehab SA (2000) Neurokinin 1 receptor expression by neurons in laminae I, III and IV of the rat spinal dorsal horn that project to the brainstem. Eur J Neurosci 12:689-700.

Todd AJ, Puskar Z, Spike RC, Hughes C, Watt C, Forrest L (2002) Projection neurons in lamina I of rat spinal cord with the neurokinin 1 receptor are selectively innervated by substance p-containing afferents and respond to noxious stimulation. J Neurosci 22:4103-4113.

Todd AJ, Spike RC, Young S, Puskar Z (2005) Fos induction in lamina I projection neurons in response to noxious thermal stimuli. Neuroscience 131:209-217.

Yaksh TL (1989) Behavioral and autonomic correlates of the tactile evoked allodynia produced by spinal glycine inhibition: effects of modulatory receptor systems and excitatory amino acid antagonists. Pain 37:111-123.

Yoshimura M, Jessell T (1990) Amino acid-mediated EPSPs at primary afferent synapses with substantia gelatinosa neurones in the rat spinal cord. J Physiol (Lond) 430:315-335. 